\title{
Strengthening the National Identity through Brands
}

\author{
Sana Imran \\ Department of Economics and Management, Khazar University, Azerbaijan
}

Copyright $(2017$ by authors, all rights reserved. Authors agree that this article remains permanently open access under the terms of the Creative Commons Attribution License 4.0 International License

\begin{abstract}
This paper is aimed to highlight the significance of 'Brands' for strengthening the 'National Identity'. It is a modest attempt to analyze how nations accrue global recognition through a systematic proliferation of national brands. Meticulously prepared advertisements and a well thought out media campaign often shape branded products into successful marketing propositions. While the use of brands in influencing the overall national image has become a marketing imperative, products of multi-national origins still remain in great demand. A fine linkage can be traced between the country of origin of a particular brand, the national identity, contribution of brand towards enhancing the national image and consumer ethno-centrism. The conceptual, strategic and practically relevant aspects of this association along with the managerial implications will be discussed in this paper, in a purely academic and research based construct, with a view to validating the following postulates: 1) Brands impact upon the construction of national identity. 2) Brands' influence on national identity is equally applicable in the spheres of diplomacy, defense, economy, trade, fashion and industry. 3) Countries have gained more fame globally, due to their branded products in all walks of life.
\end{abstract}

Keywords Competitive Identity, Country of Origin, National Identity, Nation Brand, National Image, Consumer Ethnocentrism

\section{Introduction}

The world has transformed into a global village. It has actually evolved as one big corporate or commercial market. In a globalized world, everyone is competing for his or her share of consumers, tourists, investors, students, events and entrepreneurs.

As humans, we always are not out, in the hunger to explore the world and form opinions based on our own experiences rather we stereotype people and places, based on the opinions and images that we vividly come across. Simon Anholt described this phenomenon in Competitive Identity-2007 as "We all navigate through the complexity of the modern world armed with few clichés, and they form the background of our opinions, even if we are not fully aware of this and do not always admit it to ourselves".

This approach might appear to many as being not ethically and morally correct, but with ever so changing dynamics of both the local and international market, it has become virtually impossible to go after individuals and make them understand the real complexities shrouded in the simple images set. "Country stereotypes may be negative or positive and the management of a product's national image is therefore, an important element in the strategic marketing of international firms." (M. Sadiq Sohail \& Osman Gokhan Sahin, 2010). Similarly, a connection exists between the consumer's ethnocentrism and product's country of origin. If the product stems from other country, consumer behavior is also influenced by consumers' attitude towards the product's country-of-origin (Chao, 1993, 2001; Sharma, 2011), in relation with his / her extent of ethnocentrism (Diamantopoulos et al., 2011)."

Brands have always been a mean to strengthen the national identity. "Brand distinguishes a product from its unbranded counterpart through its sum total of perceptions and feelings about the product's attributes and how it performs". (Colin Jevlons, 2005). New York, Paris and Milan are best known to the world, as fashion-originating centers. The iconic brands of USA, France, Germany and Italy reinforce the respective national identities. "Identity maybe objectified or articulated in terms of institutions, customs, practices, rituals, ceremonies, artistic and literary products, and other forms of artifact." (Yoshino 1998).

The ever so popular automotive of Germany, electrical and electronic gadgets of Japan, technologically superior and reliable cyber solutions of USA reflect on their originating countries. China storms the global markets with cost effective and affordable consumer products, bulk production and quick supply system around the globe. Huge turnover of Ali Baba is a case in point. "Ali Baba's business model takes advantage of the fact that China has been and continues to be the primary product supplier to the world." (Lui Shiying and Martha Avery, 2009). Europe emerges as the hub of global tourism, aptly projecting its mesmerizing natural beauty. Czech Republic is known for its crystal ware, Belgium for chocolates and Switzerland for its watches. 
Livestock and dairy products of Australia and New Zealand are the hallmark of these nations. Pakistan is popular for the sports goods, surgical instruments, textiles, wheat, rice and top class mangoes. Football World Cup 2014 held in Brazil was played with a Pakistan made football named "Brazuka". Similarly, oil industry tycoon of Azerbaijan SOCAR has emerged as the petro-chemical giant of Eurasia, solidifying Azerbaijan's identity at the regional and global levels. The above mentioned examples substantiate following facts:-

- Brands impact upon the construction of national identity.

- Brands' influence on national identity is equally applicable in the spheres of diplomacy, defense, economy, trade, fashion and industry.

- Countries have gained more fame globally, due to their branded products in all walks of life.

\section{Aim}

To study the phenomenon how brands contribute towards construction of national identity, covering aspects of national identity, consumer ethnocentrism, nation-branding and nation-image.

\section{Branding the Unknown}

"Branding is a core activity of capitalism" (Holt 2006, p. 300). The New York Times suggested a power statement, which had a clean sweep over the world of branding by phrasing, "Brand can be a noun (Google), an adjective (Google search engine), or more powerfully, a verb (to Google)" (Cohen 2009). However, marketing practitioners generally use the traditional definition, which has been used for brands, "A name, term, design, symbol, or any other feature, which identifies one seller's good or service as distinct from those of other sellers"(American Marketing Association - 2005).

Brand is a term, frequently used by consumers in their day to day life. Incidentally however, it is least understood by all. In a media-led milieu of today, brands can get instant global recognition. Digital models of communications make brands' existence readily felt in all spheres of life. Through social media, websites, mobile marketing and user generated content; brands can make their ingress conveniently into consumers' lives. "Brands take their shape becoming something negotiated in the space between marketer and consumer. In fact, brands are meaningless outside a notion of social construction and mediated communication." (Muñiz and O'Guinn 2005, p.64). It has gradually become difficult for the consumers of our age to neglect the ever-increasing presence of or exposure to the brands around them. Brand differentiation grew out of the need to create that unique mark of distinction required between competing products. "A linked role of brands is to provide a sustainable mean of communicating values and consequently, to maintain competitive advantage over the long term". (Jevons 2007).

The writers of cultural studies, political science, journalism and mass-communication endorse the significance of brands. "Advertisements sell more than products; they sell values, ways of life, conceptions of "self \& other" and ideologies including capitalist consumerism, imperialism, racism and patriarchy". (Hogan 2005, p.193).

In case, it is agreed that the brands are the interpretation of consumer's value for the company and that the brands are experienced and consumed through avid advertisements, the question, which comes to one's mind, is about the relationship, which brand maintains with the national identity?

\section{National Identity}

National identity is the sense of belonging one has to a state or a nation, or a sense of solidarity one feels towards a particular group, disregarding one's actual citizenship status. "A collective of people, united by shared cultural features, myths and values" (Barrington 1997). National identity is not a trait with which people are born; rather, experiences from the common lives of people that build their identity. "In the recent political philosophy, the concept of national identity has been used with increasing frequency, especially by the philosophers arguing for legitimacy of a principle of political self-determination". (Omar Dahbour, 2002).

A nation is a determinate thing. It is not defined by social facts (e.g., kinship) but by the beliefs about what those facts are (i.e., convictions about kinship ties). "National identity is a creditable form of identification. National identities are essential for maintaining self-respect, belonging, a sense of security and giving people meaning in their lives". (Nielsen 1999). A nation is necessarily an ethnically self-defined and politically self-conscious group, which is usually influenced by the factors of language, national colors, symbols, history of nation, blood connections, culture, cuisine and music etc. If one views national identity positively, it is typically called "patriotism". "A well developed and strong sense of national identity has the power to be a productive and enabling force within the society, providing positive social capital, with benefits such as improved cooperation with others, improved information flows and more effective, better functioning government and other democratic institutions". (Aldridge 2002).

\section{Effect of the Country of Origin on Brands}

Country of origin has become an inevitable part of branding in today's world. Apart from the label of "Made by" the "Made in" has become equally important. There is no denying the fact that in modern day time compressed environment, consumers set their preferences for more ready solutions in their list of needs and tend to make informed 
buying decisions. It is where the country of origin like a brand's name comes to consumers' rescue for making immediate yet informed buying decisions. Following Zhang (1996, p. 51), one can define the Country of Origin (COO) simply as "Information pertaining to where a product is made," which is usually operationalized and conveyed with the phrases like "Made in" and the country's name Amine et al, 2005).

Suffixing names of countries like Germany, Italy, Japan, Switzerland or USA, add such a colossal appeal in the overall package for consumers that it appears to be strikingly effortless. It is for the same reason that consumers tend to prefer French cheese, champagne and perfumes over any other country, German cars over USA and Chinese, Japanese electronics and electrical appliances over Mexicans, Malaysians and Koreans and Italian fashion over Finnish etcetera. "These range from the extent to which the place of manufacture influences product evaluations (Gurhan-Canli and Maheswaran, 2000), to intangible barriers to entering new markets in the form of consumer biases toward imported products (Wang and Lamb, 1983). But as Chattalas, Michael; Kramer, Thomas; Takada, Hirokazu mentions "Specifying a product's $\mathrm{COO}$ is becoming even harder, because global sourcing and manufacturing have resulted in many products having dual or multinational origins." For example, a Toshiba television may be assembled in Mexico, but it may include Japanese, Mexican, or even American parts. Concurrently however, Toshiba brand name remains associated with Japanese origin. Similarly, ADIDAS, NIKE and Levis' are typical USA's brands but are largely manufactured in China, Cambodia, Vietnam and Myanmar.

There might be events, when these associations might end up being misleading, as even in the giant countries it may become virtually impossible for the Governments to ensure the same quality standards throughout the manufacturing or service sectors. "There is a relationship between a country's general image and its product image. If a consumer has a negative image of a given country, he or she is likely to develop a similar image of the people of that country and vice versa, which in turn influences his or her attitudes toward products originating from that country in the same direction" (Morello 1984; Wang 1978).

A home country with strong, positive and universally recognized associations of trust, quality and integrity remains a major advantage to the manufacturers, as they face harsh realities of global competition. It is just like the way a new product from a well-known company is accepted by loyal consumers. The association with the 'parent brand' is such a strong delegate of consumers' prior personal experiences that it encourages the consumer trial in a favourable manner, which a new product from an unknown brand, can never experience. "Faith is often more potent than the logic and perception is often stronger than the reality: that's just the way people are."(Anholt Simon Competitive Identity 2007, p. 10).

\section{Consumers' Ethnocentrism}

Selection of foreign products from the countries having similar culture of consumer's back ground is a consequence of natural tilt. While working towards the building of a National Identity Image, the multi-dimensional construct of "Consumer Ethnocentrism" needs to be well studied for better prediction of consumer preferences. "Ethnocentrism has a more powerful influence on consumer preferences for domestic and foreign products than demographic or marketing-mix variables." (Balabanis et al., 2001, p. 159; Herche, 1994). There will always be times, when consumers will prefer domestic products over the foreign products, even if the quality is lower and the price is higher. Such a bias is attributed to the consumer's ethnocentrism. "When choosing among the foreign products, consumers manifest more favorable attitudes toward products from those countries with a similar culture." (Lanz and Loeb, 1996; Sharma et al., 1995; Watson and Wright, 2000). Such tendencies pose as a challenge for multinational companies to invest in target countries, despite having growing commercial opportunities to sell their products. "Ethnocentrism has a much greater influence on the decision to purchase goods from overseas than does a particular marketing strategy focus (i.e. lower prices, intensive distribution, etc.)" (Herche, 1994, page 12). China and Japan can be viewed as significant examples of this mind shift. Consumers appear to be shifting away from foreign products and more inclined towards the national or local ones. "Nationalism has played a significant role in China's modern history", (Xiaogang bi, sailesh gunessee, robert hoffmann, wendy hui, jeremy larner, qing-ping ma and frauke mattison Thompson, 2010). "Resurgence of Chinese nationalism since the 1990s has been well documented." (e.g. Gries, 2005; Yuan, 2008).

\section{Conceptualizing National Identity}

Many researchers of cultural studies, mass communication and journalism (Askew and Wilk 2002; Frosh 2007; Millard et al. 2002; Moreno 2003; Prideaux 2009) have conducted researches and drawn conclusions that "The media has been successful in constituting nations and is a powerful tool in building and bringing communities together". The imagined community concept recognizes the "nationally unifying power of communication technologies, particularly the print media, which allow geographically dispersed people to feel part of a single, united group. The media provides the means for circulating the stories those nations tell about themselves, and that distinguish one nation from another". (Anderson 1983). Many researchers believe that the advertising produces nationalism and informs the process of conceptualizing a nation. Cultural studies scholars have also considered the nation, with particular emphasis on television as a site of popular knowledge and the leading resource for identity projects. However, there exist doubts as to whether television can continue to be the unifier of the 
nation given the globalizing influences on programming (Barker 1999). Notwithstanding all above, brands are essentially meant to represent the nation's distinct and unique values among diverse international publics like investors, tourists, migrants, workers, scholars, arts and sports franchises.

\section{National Competitive Identity}

"National competitive identity strategy is creating a spirit of benign nationalism amongst the populace, notwithstanding its cultural, social, ethnic, linguistic, economic, political, territorial and historical divisions." (Simon Anholt, Competitive Identity, 2007). Comparing with the construct of national culture (Hofstede, 1997), national identity minimizes the relevant distinction between "culture" and "nation", and avoids the ambiguity between the two concepts (Cui and Adams, 2002). "National identity is defined as the extent to which a given culture recognizes and identifies with a set offocal elements, which set it apart from other cultures, by exhibiting greater variations in the institutions of those aspects than others" (Clark, 1990; Keillor et al., 1996). Marketing and branding combine the scientific clarity of thought and rigorous observation of human psychology, culture and society with the most elusive factor of creativity. In fact, these two bring commerce and culture together, as a potent force for creating prosperity.

\section{Nation Branding}

"Nation branding can be defined as the phenomenon by which governments engage in self- conscious activities aimed at producing a certain image of the nation state" (Bolinand Stahlberg 2010, 82). Nation branding idea is no longer an alien concept. Beginning in late 90 s and with the dawn of the new millennium, the branding of the nations has become a gripping phenomenon, which can be seen in increasing numbers of state branding campaigns. "Nation brand is the national identity made tangible, robust, communicable and above all useful." (Simon Anholt, 2008). State branding has actually become 'Brandology Business' (Van Ham - 2002). The idea of 'State Branding' is increasingly getting popular, due to its effects on economic decisions of local and international investors / consumers. State branding is generally considered as a strong tool for a nation's soft image generation. Increasing number of states are joining this bandwagon. While many nations truly comprehend and analyze the importance of being part of this branding wave 'craze', others fear that their failure to timely capitalize on state branding spree, might cause a heavy toll, in terms of an overall economic price.

Image-formation and state-branding, substantiated by the 'branding or bust' philosophy have become a must for countries around the world. Although image and state branding remain helpful in public diplomacy, nevertheless, more aspects related to marketing and branding are dovetailed by the state foreign policy makers, while crystallizing and projecting their state's foreign policy goals to international community. Since the end of the Cold War, image-building and brand-finding have been one of the key statecraft concerns of the governments in the post-Communist region. "Any state that use branding exercises as a way of changing public opinion misunderstands the tremendous power of the media to shape and mold public perceptions and the inability of the state to separate its manufactured image from our existing preconceptions." (Jonathan Rose 2010).

Numerous examples of practical application of "branding or bust philosophy" can be cited. From the year 2000, bigger states like USA and China started campaigns to project their softer images worldwide. United States invested millions of dollars to rebuild places of worship, libraries and museums, restoring ancient Korans and manuscripts in Muslim countries (Kaplan, 2005). Similarly, China launched campaign to educate its citizens about the western mannerisms, prior to the start of 2008 Olympic Games. Chinese campaign was aimed to teach people, how to properly stand in line, ban on spitting and smoking in public places, educating volunteers on how to 'properly' smile, etcetera. Such campaigns by large states aptly reflect the significance of countries' international images and importance of nation-brands. This spree is not limited to large states only, smaller states are equally concerned about their national images. Some remarks on nation branding through media are offered as under:-

"Nation branding is of critical importance to developing nations, which don't have time to wait until their image catches up with the rapid pace of their development' (Anholt, 2006).

"To prove that a country is a "reliable partner", it needs to make itself known on world stage. Nation branding is undertaken to make this happen and to stimulate inward investment, attract tourists, and boost exports" (Dinnie 2008, 17).

"Nation branding can effectively be seen as a public relations exercise of governments; it is a communication strategy, which allows governments to manage and control the image they project to the world" (Aronczyk 2008).

\section{Understanding National Image}

"National image or country image has been an important subject discussed in a variety of communication disciplines" (Luther, 2002). Sometimes a country's name adds credence to the value of the product. Economic turnaround of Japan is a brilliant success story of modern times. There was a time when "Made in Japan" carried a negative connotation for most of the consumers as most western countries considered Japanese products to be cheap, 
worthless and second rate commodities. However, with the turn of tide, Japanese products are labeled as a consequence of most up-to-date technology, highest quality, style prowess and competitive pricing. "Images of countries only ever change for two reasons: either because the country changes or because it does something to its people" (Simon Anholt, Competitive Identity, 2007). Similarly, it is also not advisable to spend efforts and money just to venture opinions as to which nation's brand image is ruling or stronger in the market. Index like National Brands Index: a financial valuation of 32 nation brands (Anholt, Simon, Figure 3.1) is an endeavor to evaluate the relative strength of national brands.

\section{Investing in National Image}

It is already ascertained that countries, which have developed strong and recognized associations of trust, quality and integrity on the global front, the manufacturers of such countries always enjoy the perks of being associated to those. In the face of globalization, it surely gives them an added advantage. The advantage is akin to a product being tagged to its parent brand. The increased trial that it experiences just because of the parent brand name support puts it way ahead in relative to a new product with no prior associations.

It is a matter of common observation that cola remains synonymous to USA, pizza to Italy, perfumeries to France, wines to Georgia, skis from Slovenia, dairy products from Australia and New Zealand and vodka from Russia. People might buy Indian accountancy software, Pakistani fabric or Swiss watches but might not be compelled to buy Pakistani wine, Turkish mobiles or Indian cars. "Having said this, it might not always be true because if there is anything more permanent or constant in marketing, that is 'change.' Attitudes can and do change very quickly". (Simon Anholt, 2007). Consumer behavior predictions have more often proved to be more wrong than right. "Marketing successes have occurred as a consequence of an inspired or obstinate marketer choosing to ignore what consumer research identified as "what consumers want." Countries have to fight for favorable attention; [because] once won, it pays political and economic dividends'. (The Economist, 25 August 2001)

\section{Taking National Image Forward}

Governments of states are trying to use popular brands for furthering nations' image worldwide. Leverage for a brand to evolve at its own, is somewhat limiting due to this growing influence. "It is no longer a question of 'to brand or not to brand' for a state's government, but rather a decision of doing the branding or going bust" (van Ham, 2002, p. 252). It is the buyers, not the sellers 'opinion which matters.
In other words, a country should be selling what the 'buyers' - that is, tourists and consumers abroad - are interested in paying for, rather than what a ' seller' - that is, a country, its politicians and population at large - decides to offer or sell. "Ad hoc brand campaigns rarely if ever bring expected 'dividends'. To be effective, image-formation not only needs to be constantly managed, but also needs to rely on time-tested marketing techniques." (Ausra Park, 2008). More often the "consumers utilize iconic brand symbolism, offered by brand communication narratives, to concretize their identities and "to enact basic status and affiliation processes" (Holt 2006a, p.357).

\section{Conclusions}

Under the media frenzy environment, a well-considered media campaign equipped with meticulously prepared advertisements moulds the branded products into successful marketing propositions. Digital models of communications like social media platforms, blog websites, mobile marketing and user generated content make the ingress of brands convenient into the consumers' lives.

Advertisements today, sell more than the products; they sell values, ways of life, conceptions of "self \& others" and ideologies that include capitalist consumerism, imperialism, racism and patriarchy". Media's role in constituting nations remains phenomenal. Media is a powerful tool in building and bringing communities together. Advertising through media contributes towards nationalism and process of conceptualizing a nation.

Brands are quite helpful in representing the nation's distinct and unique values amongst diverse international audience of investors, tourists, migrants, workers, scholars, arts and sports franchises. When used in a deliberate sequence and organized structure, brands can be used as tools for national identity development. Such a process should be a consequence of methodical strategies and well thought out courses of action.

Marketing and branding fosters the scientific clarity of thought and rigorous observation of human psychology, culture and society with the most subtle factor of creativity.

A fine linkage exists between the country of origin of a particular brand, the national identity, contribution of brand towards enhancing the national image and the consumer ethno-centrism.

There is a growing tendency amongst the consumers to set preferences for more ready solutions and informed buying decisions. Akin to a brand's name, the country of origin helps the consumers in quick and informed decision making. Suffixing the names of renowned countries add reasonable appeal in the overall package, for the customers.

A home country with strong, positive and universally recognized associations of trust, quality and integrity affords a major advantage to the manufacturers, while confronting the harsh realities of global competition. 
The demographic and marketing mix variables impact upon the consumers' choice of domestic or foreign products. Occasionally however, the attribute of ethnocentrism prevails over it and consumers prefer domestic products over the foreign products, disregarding their relatively lower quality and higher prices. A country should be selling what the 'buyers' (i.e. tourists and consumers abroad) are interested to buy rather than what a seller (i,e a country, its politicians and population at large) intends to offer or sell.

The national image leading to a competitive identity is a domineering tool in today's global environment. In an era of global businesses, global interests and global media influencing local marketing strategies, the manufactures from countries with strong and recognized global associations of trust, quality and integrity enjoy an edge over their contemporaries. Companies that cannot keep a pace with such challenges remain exposed to risk of losing their share of consumers, tourists, investors and attention.

State branding and image formation corroborated by the 'branding or bust' philosophy, have emerged as a new normal. State branding often impacts the economic decisions of local and international investors / consumers. This public relations exercise of a government is to manage national image, which they intend projecting to the world.

\section{REFERENCES}

[1] Alba, J. W. and Hutchinson, J. W. (Eds), Using the social identity approach", Advances in Consumer Research, Vol. 25, Association for Consumer Research, Provo, UT, pp. 486-491.

[2] Amine, L. S., Chao, M. and Arnold, M. (2005), "Exploring the practical effects of country of origin, animosity, and price-quality issues: two case studies of Taiwan and Acer in China", Journal of International Marketing, Vol. 13 No. 2, pp. 114-50.

[3] Anholt, Simon (Competitive Identity, 2007, pg 10).

[4] Aronczyk, M. 2008. Living the Brand: Nationality, Globality \& Identity Strategies of Branding Consultants. International Journal of Communication 2: 41-65.

[5] Ausra Park November 2008, 'Selling' a small state to the world: Lithuania's struggle in building its national image, Place Branding and Public Diplomacy 5.1 (Feb 2009): 67-84.

[6] Balabanis G, Diamantopoulos A, Mueller RD, Melewar TC. 2001. The impact of nationalism, patriotism and internationalism on consumer ethnocentric tendencies. Journal of International Business Studies vol. 32(1): $157-175$.

[7] Chattalas, Michael; Kramer, Thomas; Takada, Hirokazu The impact of national stereotypes on the country of origin effect: A conceptual framework by International Marketing Review, 01/2008, Volume 25, Issue 1.

[8] Chao, P. (1993), "Partitioning country of origin effects: consumer evaluations of a hybrid product", Journal of International Business Studies, Vol. 24 No. 2, pp. 291-306.

[9] Cohen, Noam (2009), "The Power of the Brand as Verb," New York Times, 18 July, WK5. Retrieved, from www.nytimes.com/2009/07/19/.../19cohen.html

[10] Gurhan-Canli, Z. and Maheswaran, D. (2000), "Determinants of country-of-origin evaluations", Journal of Consumer Research, Vol. 27, pp. 96-108.

[11] Holt, Douglas B (2006b), "Toward a Sociology of Branding," Journal of Consumer Culture, 299-302.

[12] Herche J. 1994. Ethnocentric tendencies, marketing strategy and import purchase behaviour. International Marketing Review. vol. 11(3): pp. 4-16.

[13] Jonathan Rose (2010) The Branding of States: The Uneasy Marriage of Marketing to Politics, Journal of Political Marketing, page 255.

[14] Jevons, Colin (2007), "Towards an Integrated Definition of "Brand"," in Proceedings of 2007 Thought Leaders International Conference on Brand Management, Leslie de Chernatony, Ed. University of Birmingham: University of Birmingham, pp. 1-10.

[15] Liu Shiying and Martha Avery, Ali Baba - The Inside story behind Jack Ma and the creation of World's Biggest Online Market place, page 196.

[16] Lantz, G. and Loeb, S. (1998), "An examination of the community identity and purchase preferences.

[17] Luther, C.A. (2002). National identities, structure, and press images of nations: The case of Japan and the United States.Mass Communication \& Society, 5(1), 57-85.

[18] Muñiz, Albert M and Hope Jensen Schau (2005), "Religiosity in the Abandoned Apple Newton Brand Community," Journal of Consumer Research, 31 (4), 737-47.

[19] M. Sadiq Sohail \& Osman Gokhan Sahin Country-of-Origin Effects on Consumers' Evaluations of Automobiles: Perspectives from a Developing Nation Journal of International Consumer Marketing, 22:245-257, 2010.

[20] Morello, G. 1984. The "made in" issue-A comparative research on the image of domestic and foreign products. European Research 12:5-21.

[21] Omar Dahbour National Identity: An Argument for the Strict Definition Public Affairs Quarterly, Vol. 16, No. 1 (Jan., 2002), pp. 17-37.

[22] Wang, C. and Lamb, C. (1983), "The impact of selected environmental forces upon consumers' willingness to buy foreign products", Journal of the Academy of Marketing Science, Vol. 11 No. 2, pp. 71-84.

[23] Wang, C.-K. 1978. The effect of foreign economic, political and cultural environmental forces on consumers' willingness to buy foreign products. PhD diss., Texas A\&M University.

[24] Zhang, Y. (1996), "Chinese consumers' evaluation of foreign products: the influence of culture, product types, and product presentation format", European Journal of Marketing, Vol. 30 No. 12 , pp. 50-69.

[25] Van Ham, P. (2002) Branding territory: Inside the wonderful words of PR and IR theory. Millennium: Journal of International Studies 31 (2): 249-269. 
[26] Xiaogang Bi, Sailesh Gunessee, Robert Hoffmann, Wendy Hui, Jeremy Larner, Qing-ping Ma and Frauke Mattison Thompson. Chinese Consumer Ethnocentrism: A field experiment Journal of Consumer Behaviour, J. Consumer Behav. 11: 252-263 (2012) Published online 9 April 2012 in Wiley Online Library (wileyonlinelibrary.com) 